\title{
Rigidity and dorsiflexion of the neck in progressive supranuclear palsy and the interstitial nucleus of Cajal
}

\author{
JUNKO FUKUSHIMA-KUDO, KIKURO FUKUSHIMA, KUNIO TASHIRO* \\ From the Department of Physiology, and Division of Neurology,* Department of Neurosurgery, Hokkaido \\ University School of Medicine, Sapporo, Japan
}

SUMMARY Rigidity and dorsiflexion of the neck are typical signs in progressive supranuclear palsy, but the responsible areas in the brain are unknown. To examine whether bilateral lesions of the interstitial nucleus of Cajal (INC) in the midbrain tegmentum contribute to the signs of patients with progressive supranuclear palsy, we have made bilateral INC lesions in cats and tried to correlate these studies with clinical and pathological data, including our case of progressive supranuclear palsy. Bilateral INC lesioned cats showed dorsiflexion of the neck and impairment of vertical eye movement, similar to progressive supranuclear palsy patients. Analysis of the previous clinical-pathological studies and our case have shown that dorsiflexion of the neck in progressive supranuclear palsy patients was correlated more with INC lesions than lesions of the basal ganglia.

Since the first description of progressive supranuclear palsy by Steele $e t a l^{1}{ }^{1}$ it has been known that rigidity and dorsiflexion of the neck with disturbances of vertical eye movements are typical features in progressive supranuclear palsy patients. Though there have been many clinical reports on impairment of vertical eye movements, ${ }^{23}$ the brain areas responsible for this characteristic neck posture and rigidity have not been clarified.

According to the pathological studies of progressive supranuclear palsy, neuronal loss and the formation of neurofibrillary tangles occur in the globus pallidus, subthalamus, substantia nigra, red nucleus and the midbrain tegmentum. Unilateral subthalamic vascular disorders cause hemiballismus, with hypotonicity of muscles, while damage to basal ganglia including putamen and globus pallidus with birth trauma cause athetosis and spasticity. ${ }^{4}$ In neither case, has neck dorsiflexion been seen. The pathological findings of Parkinson's disease disclose neuronal loss and depigmentation in the substantia nigra. Although patients with Parkinson's disease show rigidity of the musculature, their head is bowed and the trunk is bent forward, a different posture from

Address for reprint requests: J Fukushima-Kudo, MD, Department of Physiology, Hokkaido University School of Medicine, West 7, North 15, Sapporo 060, Japan.

Received 23 September 1986. Accepted 6 November 1986 that of progressive supranuclear palsy. ${ }^{5}$ Therefore, it seems unlikely that the dorsiflexion of the neck can be explained by lesions of the basal ganglia alone. In progressive supranuclear palsy patients who exhibited dorsiflexion of the neck, pneumoencephalogram and computed axial tomography (CT) have shown atrophy of the midbrain tegmentum, ${ }^{67}$ suggesting that lesions of the midbrain tegmentum may be involved in rigidity and dorsiflexion of the neck. ${ }^{89}$

The interstitial nucleus of Cajal (INC), located in the tegmentum of the rostral midbrain is a cell group lateral to the Edinger-Westphal nucleus adjacent to the periaqueductal grey. It has been found that bilateral INC lesions in cats cause dorsiflexion of the neck. ${ }^{10}$ However, the behavioural deficits of such cats were not examined in detail in the previous studies. ${ }^{10}$ In the present experiments, we have made further observations on behavioural deficits produced by bilateral INC lesions in cats to examine whether INC lesions contribute to the characteristic neck posture of progressive supranuclear palsy patients, and have tried to correlate these studies with clinical and pathological data, including our case of progressive supranuclear palsy.

The INC areas have also been shown to participate in vertical eye movements. ${ }^{11-13}$ We report that INC lesioned cats also show impairment of vertical eye movement characteristic to progressive supranuclear palsy patients. Part of our case report and results of animal experiments were presented earlier briefly. ${ }^{71415}$ 


\section{Methods}

Experiments were performed on 11 cats. Chronic bilateral lesions of the INC were made stereotaxically ${ }^{16}$ (A 4.5-6.0, $\mathrm{L} 1 \cdot 0-1 \cdot 2, \mathrm{H}-0 \cdot 1--0 \cdot 2)$ under halothane nitrous oxide anesthesia by passing $0.5 \mathrm{~mA} \mathrm{DC}$ current for $1-2 \mathrm{~min}$ at $2-4$ different points through Isonel coated steel electrodes with exposed tips of about $0.2 \mathrm{~mm}$.

To locate the INC, trains of $21,0.2 \mathrm{~ms}, 30 \mu \mathrm{A}$ cathodal pulses (at a rate of $333 / \mathrm{s}$ ) were applied. Stimulus-evoked neck muscles contraction was observed under light anaesthesia, because of the direct monosynaptic excitatory connections from the INC to the ipsilateral neck muscles (sternocleidomastoideus, splenius, biventer cerviciscomplexus). ${ }^{1718}$ All surgery was done under aseptic conditions and a head holder was installed on the skull in some of the animals. All cats were treated with antibiotics continuously for about a week after surgery. To discriminate the effect of lesions of the passing fibres that come from the structures rostral to the INC, chronic lesions of the rostral reticular formation were performed by passing $0.5 \mathrm{~mA} \mathrm{DC}$ currents for $2 \mathrm{~min}$ at lateral planes $1.5,3.0$ and $4.5 \mathrm{~mm}$ on both sides (A 6.5-7.0, H - 0.3--0.4). Vertical electrooculograms (EOGs) were recorded 2 to 3 days after surgery by using surface electrodes placed above and below one eye (DC recording). Horizontal EOGs were recorded similarly, with surface electrodes placed on the lateral aspects of both orbits. The cats were comfortably placed in a bag and the skull of each cat was fixed by the head holder during EOG recording. Behaviour of the animals that had received successful bilateral INC lesions was observed for 3 weeks after surgery at which time they were deeply anaesthetised with Nembutal $(60 \mathrm{mg} / \mathrm{kg})$ and perfused through the heart with $10 \%$ formalin. Other cats were killed similarly 1 week after surgery. The extent of the lesions in the midbrain was verified histologically, using Klüver-Barerra methods.

\section{Results}

Figure 1A illustrates the extent of lesions in four of the six cats in which lesions were made outside the INC. Lesions made in the bilateral wide areas rostral to the INC without damaging it did not cause any clear disturbances of the neck posture in three cats tested (fig 1(A)1,2). Lesions that damaged the nucleus of Darkschewitsch, periaqueductal grey and the neighbouring structures, excluding the INC did not cause impairment of the neck posture in three other cats (fig 1(A)3-5). On the other hand, typical dorsiflexion of the neck occurred in five cats, two of which are presented in fig 2 as examples. Figure 1(B) illustrates the extent of lesions of three of the five cats that caused neck dorsiflexion. The lesions covered most of the INC. The extent of lesions of the remaining two cats were similar. These results show that neck dorsiflexion resulted from lesions of bilateral INC, but that it was not caused by lesions of the neighbouring structures especially areas rostral to it, also indicating that interruption of descending fibres originating in the reticular formation rostral to the

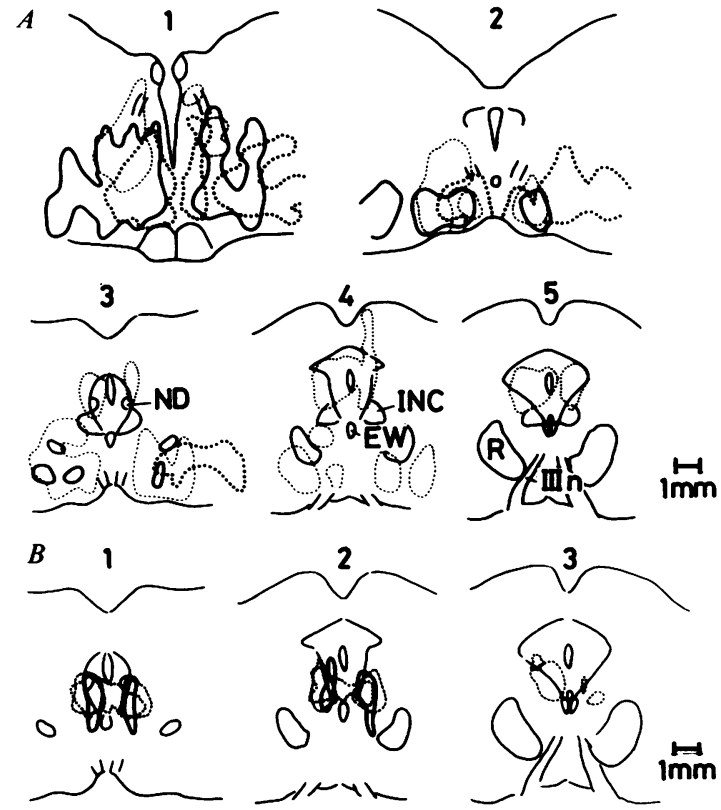

Fig 1 (A) Location of chronic lesions that did not cause dorsiflexion of the neck. Schematic cross sections of the midbrain go from rostral (1) to caudal (5). Lesions of 4 of the 6 cats that did not show impairment of neck posture are shown by different symbols. (B) Location of chronic lesions that caused dorsiflexion of the neck. Schematic cross sections of 1-3 in (B) correspond to sections 3-5 in (A). Lesions of 3 of the 5 cats that developed dorsiflexion of the neck are shown by different symbols. ND: nucleus of Darkschewitsch; EW: Edinger-Westphal nucleus; R: red nucleus; IIIn: oculomotor nerve.

INC are not responsible for the disturbance of head posture following INC lesions.

Bilateral INC lesioned cats showed upturned head posture (fig 2(A)1), and walked with neck retracted backwards. Locomotion was smooth although they showed slight stiffness of the forelimbs (fig 2(A)2). In two of them, dorsiflexion was so strong that they tended to fall backwards (fig 2(B)1). Neck dorsiflexion appeared soon after the animals recovered from the effects of anaesthesia after surgery and lasted for at least 3 weeks consistently, whether they were sitting (fig 2(A)1; (B)1), standing or walking (fig 2(A)2). Furthermore, when they drank water from a basin on the floor, the neck remained extended and was not flexed ventrally (fig 2(B)2). These observations indicate that head movement is also impaired in INC lesioned cats.

The cats' posture was observed in the dark using an infrared camera. The dorsiflexion of the neck 

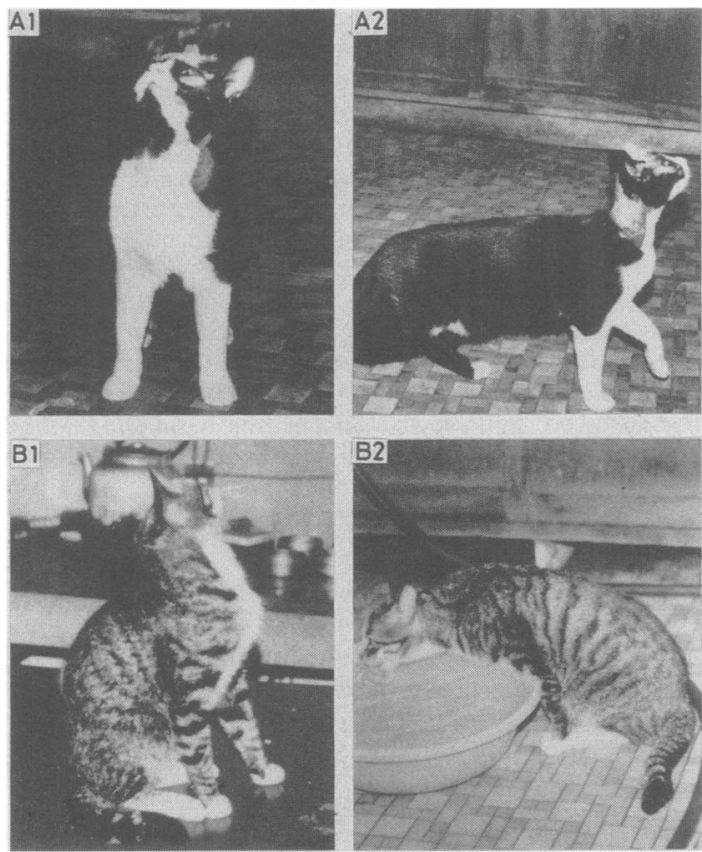

Fig 2 Photographs of 2 cats in which the bilateral INCs were lesioned. All photographs were taken 7-10 days after lesions were made.

remained unchanged without visual inputs. However, when visual inputs were allowed, and when the animals looked up at an object that was placed at the level higher than the head, the neck leaned further back and they sometimes fell over backwards. They also tended to stumble over an object placed in front of them or tended to fall from the edge of a table,

(a)
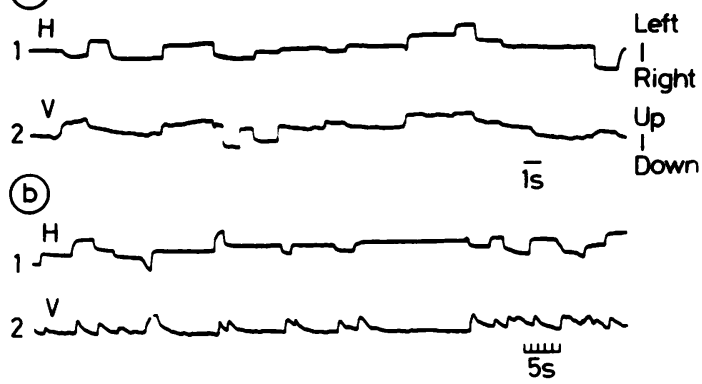

Fig 3 Effects of bilateral INC lesions on spontaneous eye movements in awake cats. Records in (a) are obtained from a normal cat. Records in (b) are obtained from the cat that had received bilateral INC lesions one week previously. The last sequence record in (b) was obtained when an auditory stimulus was given. $H$ and $V$ show horizontal and vertical eye position. when they were allowed to walk around on the table. Similar behaviour was observed in all the cats that had received bilateral INC lesions.

Figure 3, (A) and (B) shows examples of eye movements in a normal cat and a bilateral INC lesioned cat, during spontaneous saccades. Normal cats were able to maintain both horizontal and vertical eye position (fig 3(A)). Bilateral INC lesioned cats, however, could no longer maintain vertical eye position, although horizontal eye position was maintained normally (fig 3(B)). They also showed a tendency not to make downward saccades. The cats that had received extensive lesions of the reticular formation rostral to the INC (fig $1(A) 1,2)$ did not show any upward or downward saccades.

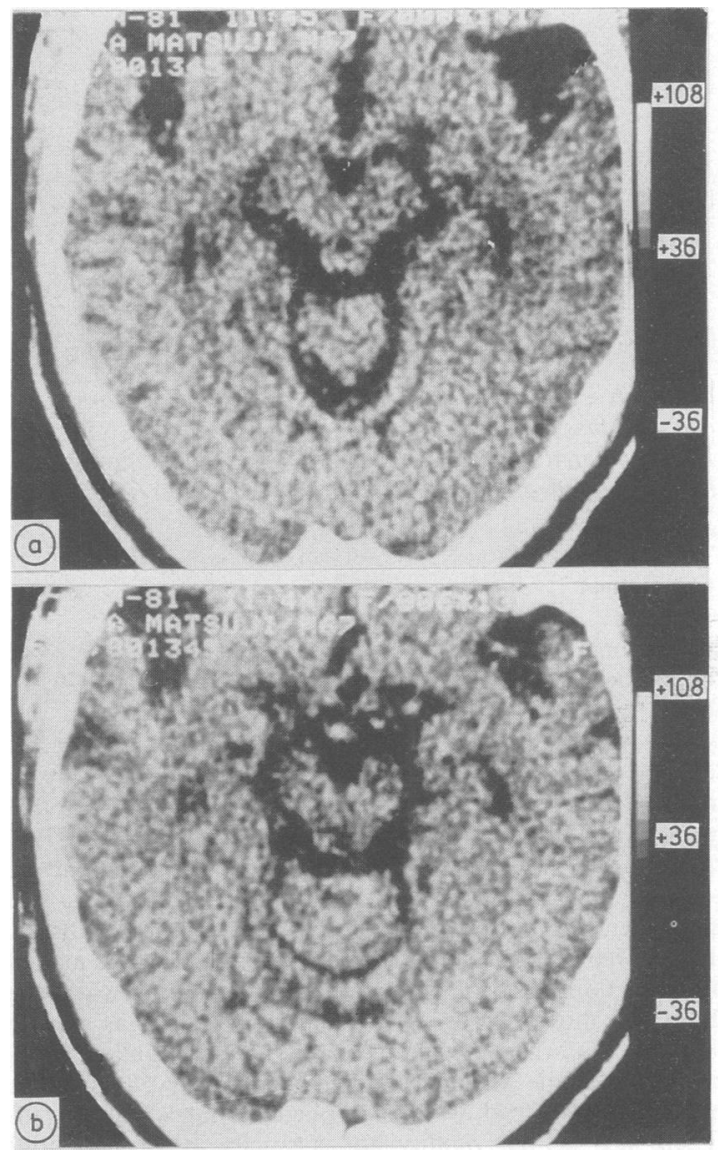

Fig 4 CT findings. (a) Horizontal section at the level of the superior colliculi. Note marked atrophy of the midbrain tegmentum. (b) Horizontal section at the level of the inferior colliculi. Enlargement of the quadrigeminal and the ambient cisterns is shown. 


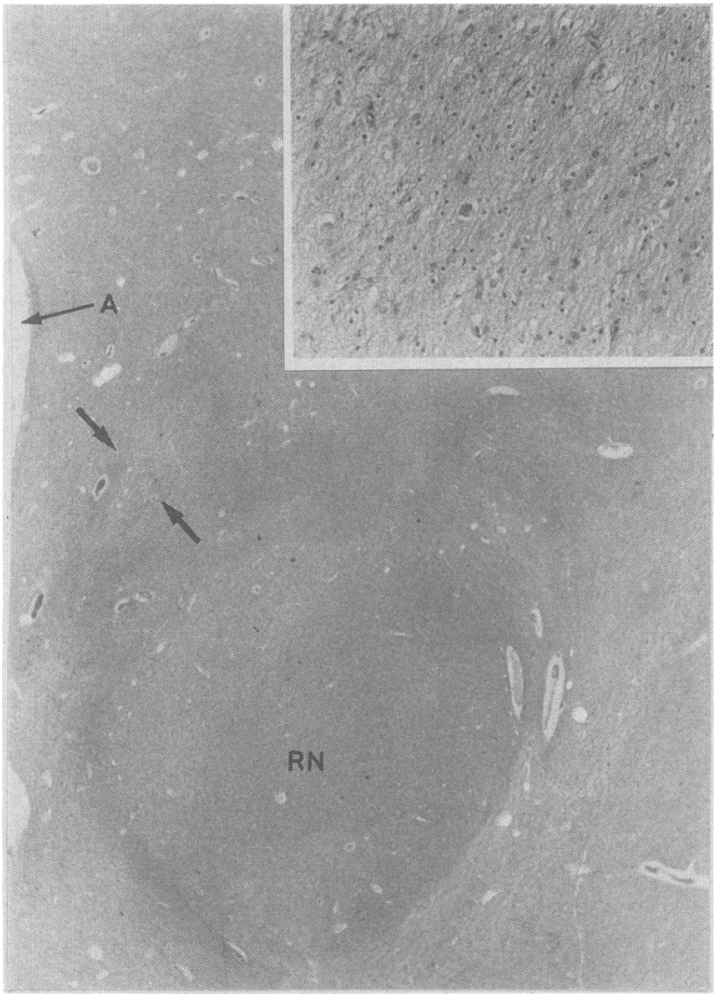

Fig 5 Necropsy finding of the midbrain, showing marked neuronal loss and astroglial proliferation in the INC. The INC is pointed by arrows. Haematoxylin-eosin stain. Insect is higher magnification $(100 \times)$. A: aqueduct. RN: red nucleus.

\section{Case report}

In summer 1978, a 67-year-old man began to have some difficulties in swallowing water and food. In spring 1979, his behaviour became slow with poor facial expression. He showed unsteadiness of gait and tended to fall backwards. He had a difficulty in reading which was not clarified by an ophthalmologist. He was admitted to the Division of Neurology in Hokkaido University Hospital on 12 May 1979.

Neurological findings Facial expression was poor and he showed monotonous speech and moderate dementia. Eye movements to vertical and the left directions were absent. Eye movements to the right were restricted. The eyes moved fully in both vertical and horizontal directions when the head was moved passively. The hearing acuity was slightly impaired and there was a mild paresis of soft palate. Movements of tongue were slow and he had mild dysphagia. Gait was unsteady and slow. Pulsion phenomenon was observed. There was neither rigidity nor spasticity in the neck and extremities initially. In October 1979, he showed emotional incontinence, rigidity in the neck and extremities with dorsiflexed neck. Neck dorsiflexion became marked and eye movements of all directions were completely absent by June 1981 .
CT findings Siemens Somatom 2 was used for CT scanning with $2 \mathrm{~mm}$ thick slices parallel to the canthal-meatal line. The axial image of the midbrain revealed marked atrophy of the tectum, especially at the level of the superior colliculi, associated with enlargement of the quadrigeminal and the ambient cisterns (fig 4). He died suddenly on 17 July 1981. Necropsy findings The brain weighed $1,320 \mathrm{~g}$ after fixation. Slight cerebral cortical atrophy with widened sulci was present. The transverse sections of the brainstem were compatible with the CT findings. Histological examinations disclosed marked neuronal loss and gliosis in the periaqueductal grey matter, superior colliculi, substantia nigra and the globus pallidus. Neurofibrillary tangles were seen in the substantia nigra, locus ceruleus, the basal ganglia and basis pontis. There was marked cell loss and proliferation of astroglia in the INC (fig 5 , pointed by arrows).

\section{Discussion}

The results of animal experiments indicate that bilateral INC lesions cause continuous dorsiflexion of the neck and impairment of vertical eye movement in cats. These may well disturb vertical gaze produced by both head and eye movement. Behavioural deficits such as stumbling over an object and falling backwards may be explained by such gaze disturbance. We will first examine the relation between INC lesions and dorsiflexion of the neck.

The characteristic cat head posture following INC lesions was produced by lesions of the INC itself (fig 1). We also produced similar dorsiflexion of the head by bilateral INC lesions with kainic acid; histology showed neuronal cell loss localised in the INC region with minimum involvement of fibres transversing the area ${ }^{19}$ suggesting that the impairment of head posture was most probably produced by damage of the INC cells.

Our clinical case which showed supranuclear ocular palsy, rigidity of the neck and extremities, dorsiflexion of the neck, gait disturbance and dementia was diagnosed as progressive supranuclear palsy according to Steele and others' criteria. ${ }^{1}$ Since the pathological findings of this case revealed the neurofibrillary tangles in several areas, this case was also diagnosed progressive supranuclear palsy pathologically. The INC was also severely involved bilaterally.

\section{Consideration of the previous clinical reports}

Table 1 summarises clinical signs and pathological findings in recent reports. ${ }^{1202123}$ Nerve cell loss was observed in the INC in patients who had developed dorsiflexion of the neck (table 1). Davis et al ${ }^{22}$ reported four cases including the case in which clinical diagnosis had not been clear before the patient's death; severe nerve cell loss was observed in the INC in Case 2 who had developed dorsiflexion of the neck, while nerve cell loss was not observed in the INC in 
Table 1 Correlation between clinical signs and nerve cell loss in the previous cases and the present one

\begin{tabular}{|c|c|c|c|c|c|c|c|c|c|c|c|}
\hline \multirow[b]{2}{*}{ Authors } & \multicolumn{4}{|c|}{ Clinical signs } & \multicolumn{7}{|c|}{ Loss of nerve cells } \\
\hline & Case & Oph & Neck & $\operatorname{Limb}$ & $E W$ & $I N C$ & $P A G$ & $R N$ & $P R F$ & $S N$ & $G P$ \\
\hline \multirow{3}{*}{$\begin{array}{l}\text { Kobayashi et } a l^{20} \\
\text { Mizutani et } a l^{21}\end{array}$} & 1 & + & + & + & ++ & $t+t$ & 1 & $+t$ & - & $+t+$ & $+t+$ \\
\hline & 1 & + & + & + & ++ & ++ & j & - & - & $+t+$ & $+t+$ \\
\hline & 2 & + & + & - & ++ & $+t+$ & i & + & - & +++ & $+t+$ \\
\hline \multirow[t]{4}{*}{ Davis et $a l^{22}$} & $\overrightarrow{1}$ & - & - & - & 1 & ++ & $+t+$ & 1 & 1 & $t+t$ & $+t+$ \\
\hline & 2 & + & + & + & i & $+t+$ & $+t+$ & i & i & $+t+$ & ++ \\
\hline & 3 & - & - & + & i & + & ++ & i & i & $+t+$ & $+t+$ \\
\hline & 4 & + & - & + & j & - & ++ & i & j & ++ & $+t+$ \\
\hline Present case & 1 & + & + & + & i & $+t+$ & $+t+$ & + & - & $+t+$ & +++ \\
\hline
\end{tabular}

Oph: ophthalmoplegia; neck: neck stiffness or neck rigidity; limb: limb rigidity; EW: Edinger-Westphal nucleus; PAG: periaqueductal grey; RN: red nucleus; PRF: pontine reticular formation; SN: substantia nigra; $G P$ : globus pallidus; $-:$ no change; $+:$ slightly changed; ++ : moderately changed; +++ : severely changed; /: not examined.

Case 4 who had not developed neck dorsiflexion. Cases 1 and 3 showed relatively mild involvement of the INC, while they did not show neck dorsiflexion. Although there is no description of the INC in the eight necropsied cases reported by Steele et $\mathrm{l}^{1}$ and Steele $^{23}$ (table 2), the cases in which lesions were found both in the periaqueductal grey (PAG) and the red nucleus (RN) suggest the involvement of the INC, since the INC in humans is also located lateral to the PAG and dorsomedial to the RN (for example in fig 5). In the cases labelled with an asterisk (Cases 1, 2, 3,5 and 6), nerve cell loss in the PAG and the RN correlated with dorsiflexion of the neck. In the cases that did not show dorsiflexion of the neck (Cases 7 and 8), the PAG and RN were not involved. In Case 4, the PAG was not examined and there was no nerve cell loss in the $\mathrm{RN}$, although the case showed dorsiflexion of the neck. The cases which had shown dorsiflexion of the neck and in which the PAG and RN were impaired were also reported. ${ }^{24-28}$

Although various degrees of nerve cell loss occurred in the substantia nigra, globus pallidus (table 1) and pontine reticular formation (table 2), there is no clear correlation between the involvement of these areas and dorsiflexion of the neck. Dubas et $a l^{29}$ reported patients who did not develop dorsiflexion of the neck and ophthalmoplegia; these cases showed severe involvement of the basal ganglia but did not reveal clear involvement of the midbrain tegmentum. From all these clinical-pathological studies, it can be said that dorsiflexion of the neck in progressive supranuclear palsy patients is more strongly correlated with the INC lesions than lesions of the basal ganglia. These studies, however, do not exclude a possibility that the combined lesions of the basal ganglia and the INC may augment rigidity of neck muscles in progressive supranuclear palsy patients, since the influence of the basal ganglia on the neck posture has not been clarified in humans.

Impairment of vertical eye movements and INC lesions The cats that had received electrolytic lesions of the bilateral INC could not sustain upward eye position although they could make upward saccades. They also had a tendency not to look downwards (fig 3(B)). $\mathrm{Cogan}^{30}$ reported a progressive supranuclear palsy patient who had paralysis of downward eye movement and who could not sustain upward eye position.

Table 2 Correlation between clinical signs and pathological findings (nerve cell loss) in the cases of Steele et al (1964) and Steele (1972)

\begin{tabular}{|c|c|c|c|c|c|c|c|c|c|}
\hline \multirow[b]{2}{*}{ Case } & \multicolumn{3}{|c|}{ Clinical signs } & \multicolumn{6}{|c|}{ Loss of nerve cells } \\
\hline & $O p h$ & Neck & $\operatorname{Limb}$ & $E W$ & $P A G$ & $R N$ & $P R F$ & $S N$ & $G P$ \\
\hline $\begin{array}{l}1^{*} \\
2^{*} \\
3^{*} \\
4 \\
5^{*} \\
6^{*} \\
7 \\
8\end{array}$ & $\begin{array}{l}+ \\
+ \\
+ \\
+ \\
+ \\
+ \\
+ \\
+\end{array}$ & $\begin{array}{l}+ \\
+ \\
+ \\
+ \\
+ \\
+ \\
- \\
-\end{array}$ & $\begin{array}{l}- \\
- \\
- \\
+ \\
+ \\
+ \\
- \\
+\end{array}$ & $\begin{array}{l}- \\
- \\
- \\
+ \\
- \\
- \\
-\end{array}$ & $\begin{array}{l}+++ \\
+++ \\
++ \\
1 \\
+ \\
++ \\
-\end{array}$ & $\begin{array}{l}+t \\
+t \\
t+ \\
- \\
+ \\
+t \\
-\end{array}$ & $\begin{array}{l}++ \\
++ \\
++ \\
- \\
- \\
++ \\
+ \\
+\end{array}$ & $\begin{array}{l}+++ \\
+++ \\
++ \\
++ \\
+++ \\
+ \\
++ \\
+++\end{array}$ & $\begin{array}{l}++ \\
++ \\
+ \\
+ \\
+ \\
++ \\
+ \\
+\end{array}$ \\
\hline
\end{tabular}

The cases with asterisk show dorsiflexion of the neck and loss of nerve cells both in the periaqueductal grey and the red nucleus. The same abbreviations are used as in Table 1 . 
The disturbance of eye movement of the INC lesioned cats (fig 3(B)) and the progressive supranuclear palsy patients are quite similar.

It is well known that neurons generating vertical saccades (burst neurons) are located in the rostral interstitial nucleus of the medial longitudinal fasciculus (MLF) which is rostral to the INC, and that lesions of that area cause paralysis of vertical saccades in monkeys. ${ }^{31}$ Our present observations in cats show that electrolytic lesions of the rostral reticular formation which corresponds to the rostral interstitial nucleus of the MLF in monkeys also cause paralysis of both upward and downward saccades (fig 1(A) 1,2). Recent studies show that fibres which come from the rostral interstitial nucleus of the MLF pass through the INC region to the extraocular motoneurons that innervate the superior oblique muscles. ${ }^{32}$ This suggests that the tendency not to make downward saccades in the INC lesioned cats in our experiments might result from interruption of the descending fibres originating in the rostral interstitial nucleus of the MLF passing through the INC region to oculomotoneurons that subserve downward saccades. On the other hand, the INC region contains neurons that discharge in relation to vertical eye position (bursttonic and tonic neurons). ${ }^{11}$ Therefore, the inability to sustain vertical eye position during saccades may be caused by lesions of the INC itself. ${ }^{19}$

\section{Rigidity and dorsiflexion of the neck}

In our progressive supranuclear palsy case, rigidity of the neck and extremities appeared simultaneously. Although dorsiflexion and rigidity of the neck developed simultaneously in the previous reports, ${ }^{1}$ rigidity of the extremities and dorsiflexion of the neck did not always appear at the same time. Moreover in some cases, ${ }^{1}$ rigidity of the neck appeared without rigidity of the extremities in the early stage. Levodopa was reported to be effective against rigidity of the extremities but not that of the neck, ${ }^{33}$ while methysergide (a serotonin antagonist) improved rigidity and dorsiflexion of the neck. ${ }^{9}$ These reports suggest that different mechanisms are involved in rigidity of the neck and of the extremities.

It is unknown by what mechanisms INC lesions cause dorsiflexion of the neck in cats. Interruption of direct interstitiospinal fibres projecting to the neck is not responsible for it, because in spite of the fact that interstitiospinal fibres have direct excitatory synaptic connections with motoneurons innervating dorsal neck muscles, reversible lesion of the INC by procaine infusion in awake cats produced an increase in the electromyographic activity of the dorsal neck muscles. ${ }^{10}$ It is also unlikely that interruption of INC projections to the rostral structures (for example basal ganglia) produced dorsiflexion of the neck, since the cats that had received electrolytic lesions of the reticular formation rostral to the INC did not show the impairment of head posture (fig $1(A)$ ). It is possible that the INC sends inhibitory projections to other brainstem region directly or indirectly which tonically excite the activity of the dorsal neck muscles, and that INC lesions result in activation of that region, causing a hypertonia of these muscles, thereby producing dorsiflexion of the neck. ${ }^{19}$

The dorsal neck muscles in humans as well as in cats work as antigravity muscles, ${ }^{34}{ }^{35}$ since in both species the orientations of the cervical vertebral column are vertical when animals are at rest. ${ }^{36}$ This suggests that basically a similar mechanism is involved in the control of antigravity neck muscles between these two species. The similarity in the head posture between bilateral INC lesioned cat's and patients with progressive supranuclear palsy may be due to manifestation of an impairment of control over the activity of cervical muscles in both species. The tendency that both bilateral INC lesioned cats and progressive supranuclear palsy patients including our case fall backwards might partly result from hypertonia in the dorsal neck muscles.

The present results also show that dorsiflexion of the neck in cats occur without visual inputs, although the abnormal head posture may be reinforced by visual inputs, similar to the symptoms in progressive supranuclear palsy. In humans, we presume that the INC lesions might cause both dorsiflexion of the neck and the impairment of sustaining vertical eye position. These symptoms may well disturb vertical gaze produced by both head and eye movement as observed in bilateral INC lesioned cats. Clinical symptoms such as stumbling over objects and falling backwards observed in progressive supranuclear palsy patients may be at least partly explained by INC lesions.

The authors thank Professor $M$ Kato of the Department of Physiology for his support of the experiments. A part of this study was supported by grants $(58106005,58570045)$ from the Ministry of Education, Science and Culture of Japan.

\section{References}

I Steele JC, Richardson JC, Olzewski J. Progressive supranuclear palsy. Arch Neurol 1964;10:333-59.

2 Pfaffenbach DD, Layton DD, Keans TP. Ocular manifestations in progressive supranuclear palsy. Am J Ophthalmol 1972;74: 1179-84.

3 Troost BT, Daroff RB. The ocular motor defects in progressive supranuclear palsy. Ann Neurol 1977;2:397-403.

4 Cote L. Basal ganglia and the extrapyramidal motor system. In: Kandel ER, Schwartz JH, eds. Principles of Neural Science. lst ed. London: Edward Arnold, 1982:352.

5 Yahr MD. Parkinsonism. In: Rowland LP, eds. Merritt's Text- 
book of Neurology. 7th ed. Philadelphia: Lea \& Febiger, 1984:526-37.

6 Tashiro K, Hamada T, Iwasaki Y, et al. Progressive supranuclear palsy: Report of two cases with special reference to its clinical manifestations and pneumoencephalo-tomographic findings (in Japanese). Brain Nerve (Tokyo) 1977;29:561-7.

7 Moriwaka F, Naganuma M, Warabi T, Tashiro K, Miyasaka K. Progressive supranuclear palsy - comparison of high resolution CT with autopsy findings-(in Japanese). Neurol Med (Tokyo) 1982;17:190-2.

8 Behrman S, Carroll JD, Janota I, Matthews WB. Progressive supranuclear palsy: clinico-pathological study of four cases. Brain 1969;92:663-78.

9 Rafal RD, Grimm RJ. Progressive supranuclear palsy: functional analysis of the response to methysergide and antiparkinsonian agents. Neurology 1981;31:1507-18.

10 Fukushima K, Takahashi K, Kudo J, Kato M. Interstitialvestibular interaction in the control of head posture. Exp Brain Res 1985;57:264-70.

11 King WM, Fuchs AF, Magnin M. Vertical eye movement-related responses of neurons in midbrain near interstitial nucleus of Cajal. J Neurophysiol 1981;46:549-62.

12 Anderson JH, Precht W, Pappas C. Changes in the vertical vestibuloocular reflexes due to kainic acid lesions of the interstitial nucleus of Cajal. Neurosci Lett 1979;14:259-64.

13 King WM, Leigh RJ. Physiology of vertical gaze. In: Lennerstrand G, et al, eds. Functional Basis of Ocular Motility Disorders. Oxford: Pergamon, 1982:267-76.

14 Fukushima K, Takahashi K, Fukushima J, Kimura T, Kato M. Effect of lesion of the interstitial nucleus of Cajal (INC) on the vertical vestibuloocular reflex (VOR) in the cat. Neurosci Res 1986; abstract 3:S61.

15 Kudo J, Fukushima K, Kato M, Tashiro K. Dystonic extensor rigid posturing of neck in progressive supranuclear palsy and the lesions in the interstitial nucleus of Cajal (in Japanese). Clin Neurol (Tokyo) abstract 1986;26:641.

16 Berman AL. The brainstem of the cat. A cytoarchitectonic atlas with stereotaxic coordinates. Madison Milwaukee, the University of Wisconsin Press, 1968:58-9.

17 Fukushima K, Pitts NG, Peterson BW. Direct excitation of neck motoneurons by interstitiospinal fibers. Exp Brain Res 1978;32:471-89.

18 Fukushima K, Hirai N, Rapoport S. Direct excitation of neck flexor motoneurons by the interstitiospinal tract. Brain Res 1979:160:358-62.

19 Fukushima K. The interstitial nucleus of Cajal and its role in the control of movements of head and eyes. Progress in Neurobiology (in press).

20 Kobayashi M, Iijima M, Hatano M, Akai K, Yoshikura N. An autopsy case of progressive supranuclear palsy with Lafora like intraneuronal inclusions (in Japanese). Ad Neurol Sci (Tokyo) 1975; 19:384-95.

21 Mizutani T, Sato J, Morimatsu Y. Clinicopathological study of eye movement of progressive supranuclear palsy (in Japanese). Clin Neurol (Tokyo) 1985;25:355-63.

22 Davis PH, Bergeron C, McLachlan DR. Atypical presentation of progressive supranuclear palsy. Ann Neurol 1985;17:337-43.

23 Steele JC. Progressive supranuclear palsy. Brain 1972;95: 693-704.

24 David NJ, Mackey EA, Smith JL. Further observations in progressive supranuclear palsy. Neurology 1968;18:349-56.

25 Anzil AP. Progressive supranuclear palsy. Case report with pathological findings. Acta Neuropathol (Berl) 1969;14:72-6.

26 Blumental H, Miller C. Motor nuclear involvement in progressive supranuclear palsy. Arch Neurol 1969;20:362-7.

27 Jellinger K. Progressive supranuclear palsy (Subcortical argyrophilic dystrophy). Acta Neuropathol (Berl) 1971;19:347-52.

28 Powell HC, London GW, Lampert PW. Neurofibrillary tangles in progressive supranuclear palsy. Electron microscopic observations. J Neuropathol Exp Neurol 1974;33:98-106.

29 Dubas F, Gray F, Escourolle R. Maladie de Steele-RichardsonOlszewski sans ophtalmoplegie. Rev Neurol (Paris) 1983;139: 407-18.

30 Cogan DC. Paralysis of down-gaze. Arch Ophthalmol 1974;91:192-9.

31 Büttner-Ennever JA, Büttner U, Cohen B, Baumgartner G. Vertical gaze paralysis and the rostral interstitial nucleus of the medial longitudinal fasciculus. Brain 1982;105:125-49.

32 Nakao S, Shiraishi Y. Direct excitatory and inhibitory synaptic inputs from the medial mesodiencephalic junction to motoneurons innervating extraocular oblique muscles in the cat. Exp Brain Res 1985;61:62-72.

33 Klawans HL, Jr, Ringel SP. Observations on the efficacy of L-DOPA in progressive supranuclear palsy. Eur Neurol 1971;5:115-29.

34 Smith JW. The forces operating at the human ankle joint during standing. J Anat 1957;91:545-64.

35 Mori S. Postural control mechanisms (in Japanese). In: Ito M, ed. Nokagaku no tenkai. Tokyo: Heibonsya 1985:14765.

36 Vidal PP, Graf W, Berthoz A. The orientation of the cervical vertebral column in unrestrained awake animals. Exp Brain Res 1986;61:549-59. 